\title{
Nutrient regulation of human intestinal sugar transporter (SGLT1) expression
}

\author{
J Dyer, K B Hosie, S P Shirazi-Beechey
}

\begin{abstract}
Background-The activity of most intestinal nutrient transporters is adaptively regulated by the type and amounts of nutrients entering the intestinal lumen. The concentration and activity of the intestinal $\mathrm{Na}^{+} /$glucose cotransporter (SGLT1) are regulated by dietary sugars in most animal species. The activity and abundance of SGLT1 in biopsy specimens removed from human jejunal regions exposed to, and having limited access to, luminal nutrients have been measured and compared.
\end{abstract}

Aims-To study the effects of luminal nutrients on the expression of SGLT1 in the human intestine.

Patient and Methods-Brush border membrane vesicles (BBMV) were prepared from biopsy specimens removed from the intestine of a 50 year old man who had developed a high output jejunal fistula, and adjacent mucosal fistula, a condition present for 12 months after surgery for a strangulated hernia. BBMV prepared from intestine exposed to luminal nutrients, and from dysfunctional intestine with a limited exposure to nutrients, were used to measure $\mathrm{Na}^{+}$ dependent glucose transport and abundance of SGLT1 protein.

Results-The levels of SGLT1 activity and abundance in the BBMV prepared from control biopsy specimens were similar to those found in BBMV prepared from the intestine of healthy individuals. BBMV from the dysfunctional intestine, exposed to limited levels of luminal nutrients, had reduced levels of SGLT1 activity. This reduction in SGLT1 activity and abundance was above that associated with any villus atrophy, as assessed by the abundance/activity of lactase and villin concentrations.

Conclusions-These data indicate that the activity and expression of SGLT1 in human intestine is maintained by the presence of luminal nutrients.

(Gut 1997; 41: 56-59)

Keywords: human intestine; SGLT1; gene expression; nutrient regulation; GLUT5

Dietary sugars, D-glucose and D-galactose, are absorbed from the lumen of the intestine across the brush border membrane into the enterocytes by the $\mathrm{Na}^{+}$/glucose cotransporter (SGLT1). The energy for this step is obtained by coupling sugar transport to $\mathrm{Na}^{+}$and electrochemical gradients. SGLT1 is a glycosylated integral membrane protein, with an apparent molecular mass of $75-80 \mathrm{kDa}$. It has been cloned from the intestinal tissues of rabbit, lamb and human. ${ }^{1-3}$ They all share an extraordinary degree of homology. ${ }^{4}$

Clinical interest in the intestinal brush border SGLT1 has focused mainly on malabsorption syndrome - that is, glucosegalactose malabsorption ${ }^{5}$ and diarrhoea. ${ }^{6}$ In diarrhoea induced by agents such as Vibrio cholerae and Escherichia coli, the most effective treatment is oral rehydration therapy ${ }^{6}$ which relies on the ability of glucose to activate intestinal salt (and water) absorption via the SGLT1.

It is well established that monosaccharides in the lumen of the intestine regulate the activity and abundance of SGLT1 in the intestinal brush border membrane of various animals. ${ }^{78}$ Advances in the molecular and cellular biology of intestinal sugar transport, and their application to an appropriate animal model, have increased our understanding of the molecular mechanisms involved in the regulation of SGLT1 by sugar components of the diet. ${ }^{49}$ The assessment of similar mechanisms regulating human intestinal SGLT1 has been impeded by difficulties in experimentally manipulating human subjects.

We have had an opportunity to screen the activity and abundance of SGLT1 in the proximal intestine of a 50 year old man with jejunostomy and mucosal fistula, present for 12 months after surgery for a strangulated hernia.

\section{Methods}

REMOVAL AND STORAGE OF INTESTINAL TISSUE An otherwise fit and well 50 year old white man developed a high output proximal jejunal fistula, with adjacent mucosal fistula, after surgery for a strangulated incisional hernia. The corrective surgery was performed 12 months after the formation of the fistula. Before re-anastomosis of the jejunum, three biopsy samples (each $30-40 \mathrm{mg}$ wet weight) were taken from the proximal intestine exposed to luminal nutrients, and three removed from the adjacent dysfunctional jejunum exposed to a limited overflow of nutrients. After removal, the biopsy specimens were placed immediately in marked microfuge tubes and frozen in liquid nitrogen. They were subsequently stored at $-80^{\circ} \mathrm{C}$ until use.

An additional set of fresh biopsy samples, taken from both regions of the intestine, were 
fixed in formol saline. Histological examination revealed that the tissues were structurally intact.

Permission was obtained from the Sheffield and East Dyfed Health Authorities for this study and prior consent of the patient was secured.

PREPARATION OF BRUSH BORDER MEMBRANE VESICLES FROM INTESTINAL BIOPSY SAMPLES Brush border membrane vesicles (BBMV) were prepared from the cellular homogenates using a combination of cation precipitation and differential centrifugation techniques as outlined before. ${ }^{10}$ The final purified BBMV were suspended in $5-10 \mu l$ of a buffer containing $300 \mathrm{mM}$ mannitol, $20 \mathrm{mM}$ HEPES/Tris, $\mathrm{pH} 7 \cdot 4$, and $0 \cdot 1 \mathrm{mM} \mathrm{MgSO}_{4}$, using a 27 gauge needle. BBMV were then stored in liquid nitrogen until use. The final protein concentration of the BBMV amounted to $10-20 \mathrm{mg} / \mathrm{ml}$.

ESTIMATION OF PROTEIN

The protein concentration in the BBMV was estimated by its ability to bind Coomassie blue according to the BioRad microassay technique. Bovine $\gamma$-globulin (1-15 $\mu \mathrm{g}$ protein) was used as the standard. ${ }^{211}$

MEASUREMENT OF $\mathrm{Na}^{+}$DEPENDENT D-GLUCOSE TRANSPORT ACTIVITY

The initial rate of $0 \cdot 1 \mathrm{mM}$ D-glucose transport in BBMV isolated from biopsy samples was measured at $37^{\circ} \mathrm{C}$ in the presence of either $\mathrm{NaSCN}$ or KSCN, using the rapid filtrationstop technique, as described previously. ${ }^{10}$

MEASUREMENT OF DISACCHARIDASE ACTIVITY The specific activities of sucrase and lactase were measured as described previously. ${ }^{10-12}$ Lactase was assayed in the presence of $0.2 \mathrm{mM}$ $\rho$-chloromeruribenzoate to inhibit any potential lysosomal $\beta$-galactosidase activity that may be present. ${ }^{13}$

QUANTITATIVE IMMUNODETECTION OF SGLTI The abundance of SGLT1 protein was measured using quantitative western blotting as described previously. ${ }^{14}$ The protein contents of BBMV were separated on an $8 \%$ polyacrylamide gel containing $0 \cdot 1 \%$ SDS and were electrotransferred to nitrocellulose membrane (Trans-Blot, BioRad). ${ }^{9}$ Pre-stained molecular weight markers (Seeblue, Novex) permitted quantitative estimation of the efficiency of electrotransfer to nitrocellulose.

The synthetic peptide, which corresponds to amino acids $402-420$ of SGLT1, was used as the standard. This nonadecapeptide is the antigen used for the production of the SGLT1 antibody. ${ }^{249} \mathrm{~A}$ range of peptide standards (0.01-6 pmol) was slot blotted onto a nitrocellulose membrane and probed with the SGLT1 antibody, concurrently with the
BBMV samples. ${ }^{14}$ The specific immunoreactive band was blocked when antibodies were pre-incubated with the immunising peptide. The nitrocellulose membranes were then developed using the ECL system (Amersham, Little Chalfont, UK), and exposed to film (XOMAT-LS, Kodak).

The intensity of immunoreactive bands detected in the BBMV and the peptide standard samples was quantified using scanning densitometry (Phoretix), and the abundance of SGLT1 protein per mg of brush border membrane protein was calculated from the peptide standard curve.

ESTIMATION OF FRUCTOSE TRANSPORTER (GLUT5), SUCRASE, VILLIN, AND LACTASE ABUNDANCE

The same nitrocellulose membrane in which the BBMV samples were immunoblotted with the SGLT1 antibody was stripped by washing in $137 \mathrm{mM} \mathrm{NaCl}, 20 \mathrm{mM}$ glycine/ $\mathrm{HCl}$ buffer, $\mathrm{pH} 2 \cdot 5$. The membrane was then probed with a monoclonal antibody raised against villin ${ }^{15}$ (The Binding Site, Birmingham, UK). After re-stripping and removal of the antibody directed against villin, the blot was re-probed with an antibody raised against the C-terminal amino acid sequence of human GLUT5 (Biogenesis Ltd, UK). The membrane was then re-probed with the antibody against sucrase. ${ }^{16}$ Finally, the stripped membrane was probed with a monoclonal antibody against lactase. ${ }^{17}$ The abundance of the immunoreactive bands, at $95 \mathrm{kDa}$ for villin, ${ }^{15}$ at $47 \mathrm{kDa}$ for GLUT5, ${ }^{18}$ at $150 \mathrm{kDa}$ for sucrase, ${ }^{16}$ and at $160 \mathrm{kDa}$ for lactase, ${ }^{17}$ was measured by scanning densitometry (Phoretix).

\section{STATISTICS}

Data are expressed as mean (SEM) for measurements on multiple biopsy specimens taken from control and dysfunctional regions of the intestine of a single individual. Statistical comparisons are made using the Student's unpaired $t$ test.

\section{Results and Discussion}

Using various animal model systems, several laboratories have shown that the activity and expression of intestinal SGLT1 is regulated by dietary sugars. ${ }^{4-9}$

Manipulation of the carbohydrate content of diets fed to rats and mice indicated that the sugar content of the diet modulates the activity of intestinal SGLT $1 .{ }^{7}$ Furthermore, the ovine small intestine, a unique model system for studies on the regulation of intestinal SGLT1 by luminal sugars, ${ }^{48919}$ has facilitated major advances to be made in the understanding of how monosaccharides in the lumen of the intestine regulate the activity and expression of SGLT $1 .{ }^{4} 19$ In ruminant animals, such as sheep, as the diet changes from milk to grass the rumen develops. Dietary carbohydrates are fermented, by the rumen microflora, into volatile fatty acids. Rumen development is 

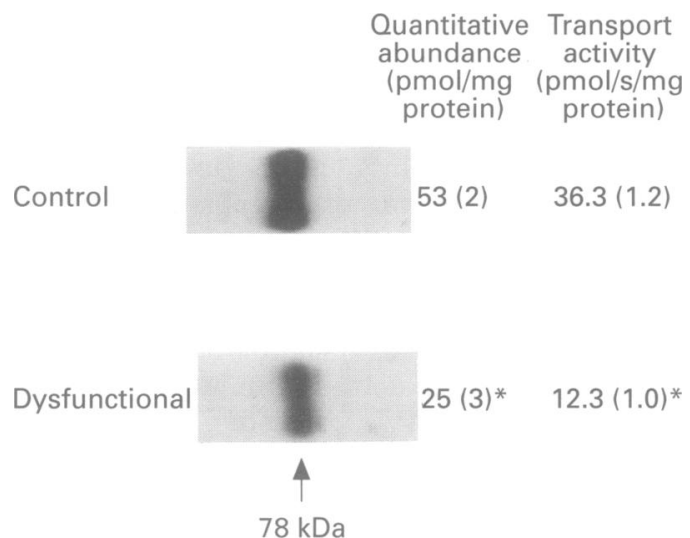

Figure 1: The activity and abundance of SGLT1 in $B B M V$ prepared from control and dysfunctional human jejunum. BBMV (10 $\mu \mathrm{g}$ per lane) were separated on an $8 \%$ polyacrylamide gel and electrotransferred to nitrocellulose. Samples were immunoblotted with an antibody raised against SGLT1, and the results were quantified as described in Methods. The initial rate of the $\mathrm{Na}^{+}$dependent, phlorizin sensitive, transport of D-glucose was also measured in these vesicles at $37^{\circ} \mathrm{C}$. Results are expressed as mean (SEM). ${ }^{*} p<0.005$.

therefore a natural and efficient way of ensuring a virtual block in the delivery of monosaccharides to the small intestine. There is a notable decrease in the activity and expression of SGLT1 associated with this change in carbohydrate digestion. ${ }^{914} 20 \mathrm{We}$ have shown that the introduction of $\mathrm{D}$-glucose, and a range of $\mathrm{D}$-glucose analogues, into the luminal contents of ruminant ovine intestine stimulates the synthesis of functional SGLT $1 .{ }^{9}$ The luminal sugar signal is perceived by a sugar sensor which has a different sugar specificity from that of SGLT1. ${ }^{419}$ The transduced signal, through a cascade of intracellular events, leads to the transcription of the SGLT1 gene, translation of SGLT1 mRNA, and the insertion of functional SGLT1 protein into the brush border membrane of the enterocyte. ${ }^{4}$

Although information on the structure of the gene encoding human SGLT $1,{ }^{3}$ and the missense mutation in the SGLT1 gene causing glucose-galactose malabsorption ${ }^{5}$ has increased, no detailed studies have been carried out on the mechanisms by which dietary sugars
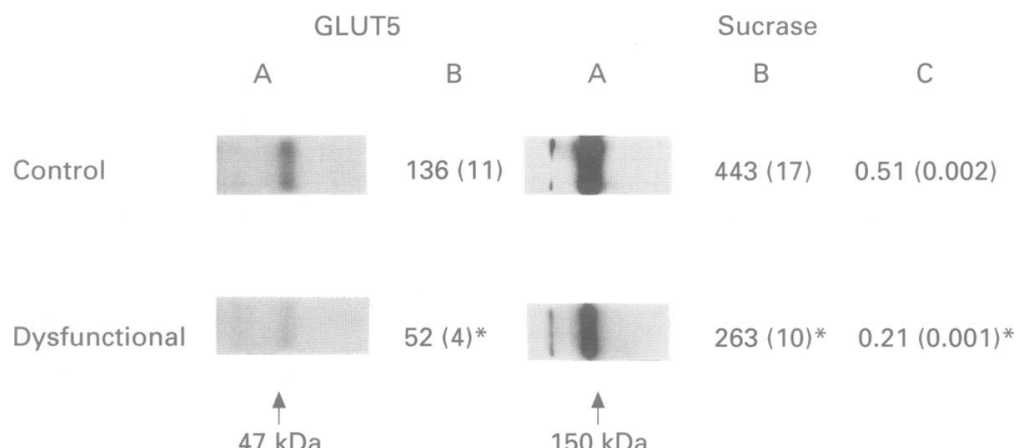

$52(4)^{*}$

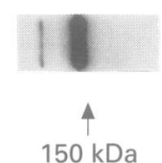

$263(10)^{*} \quad 0.21(0.001)^{*}$

Figure 2: Abundance of GLUT5 and the activity and abundance of sucrase in BBMV prepared from control and dysfunctional human jejunum. The same blot as probed with the SGLT1 antibody was stripped and immunoblotted with antibodies raised against sucrase and GLUT5. Specific immunoreactive bands $(A)$ were quantified by scanning densitometry (Phoretix) and the results are presented as arbitrary units (B). Sucrase specific activities, $\mu \mathrm{mol} / \mathrm{min} / \mathrm{mg}$ protein, (C) are given as mean (SEM). ${ }^{{ }_{p}}<0.005$. control the expression of SGLT1 in human intestine.

The development of a technique to prepare purified BBMV from intestinal biopsy samples has permitted the measurement SGLT1 activity in various regions of the human intestine. ${ }^{10}$ The cloning and sequencing of the SGLT1 cDNA and determination of the amino acid sequence has permitted the production of specific antibodies to SGLT1. ${ }^{29}$ The availability of these antibodies permits estimation of the abundance of this protein in human intestinal brush border membrane. However, owing to difficulties in the experimental manipulation of human subjects, the direct effects of dietary changes on the expression of human intestinal SGLT1 have not been studied in detail.

In this study we have measured the abundance and activity of SGLT1 in the intestine of a man who had developed a postoperative, high output, jejunal fistula, with adjacent jejunal mucosal fistula. BBMV were isolated from biopsy samples taken from the proximal jejunum exposed to luminal nutrients, and from the adjacent dysfunctional jejunum which had a limited supply of luminal nutrients.

Figure 1 presents the activity and quantitative abundance of SGLT1 measured in BBMV isolated from these biopsy samples. The activity and the abundance of SGLT1 in $\mathrm{BBMV}$ isolated from the nutrient replete tissue (control) was $36 \cdot 3(1 \cdot 2) \mathrm{pmol} / \mathrm{s} / \mathrm{mg}$ protein and 53 (2) $\mathrm{pmol} / \mathrm{mg}$ protein, respectively. These parameters in dysfunctional tissue were 12.3 $(1 \cdot 0) \mathrm{pmol} / \mathrm{s} / \mathrm{mg}$ protein and 25 (3) $\mathrm{pmol} / \mathrm{mg}$ protein, respectively.

In order to determine whether these changes in the levels of SGLT1 expression are related to any modifications in the intestinal structure, we measured the concentrations of other brush border membrane absorptive and digestive proteins, and the structural protein villin, in the same BBMV sample isolated from the two intestinal regions. Figures 2 and 3 summarise the results. The activity and the abundance of the fructose transporter (GLUT5) and sucrase are known to be regulated by the levels of dietary nutrients, ${ }^{21-23}$ whereas the expression of lactase is a "pre-programmed" event and is independent of any changes in luminal nutrients. ${ }^{12} 16192223$

In the BBMV isolated from the dysfunctional tissue, there was a twofold decline in the specific activity and abundance of sucrase and a 2.6-fold decrease in the abundance of GLUT5 protein (fig 2) compared with control tissue.

The abundance of villin in the BBMV isolated from the nutrient replete tissue (control) was 206 (3) units, as measured by scanning densitometry. The level remained constant in BBMV isolated from the nutrient limited dysfunctional tissue. Villin is the major protein associated with actin in the microfilament core of the enterocyte brush border, ${ }^{24}$ and any changes in the intestinal structure would be reflected in the concentrations of this protein. Furthermore, the 


\begin{tabular}{|c|c|c|c|c|c|}
\hline & & $\operatorname{lin}$ & & Lactase & \\
\hline & A & B & A & B & C \\
\hline Control & & $210(2)$ & & $372(9)$ & $0.14(0.001)$ \\
\hline Dysfunctional & & $203(5)$ & & $376(4)$ & $0.15(0.007)$ \\
\hline & 4 & & 4 & & \\
\hline & $95 \mathrm{~kL}$ & & $160 \mathrm{~kL}$ & & \\
\hline
\end{tabular}

Figure 3: The abundance of villin and the activity and abundance of lactase in BBMV prepared from control and dysfunctional human jejunum. The same blot verified sequentially with antibodies against SGLT1, sucrase and GLUT 5 was stripped and probed with the antibodies against villin and lactase. The abundance of the specific immunoreactive bands $(A)$ were quantified as before and are presented as arbitrary units (B). Lactase specific activities, $\mu \mathrm{mol} / \mathrm{min} / \mathrm{mg}$ protein, $(C)$ are given as mean (SEM). ${ }^{\star} p<0.005$.
1 Hediger MA, Coady MJ, Ikeda TS, Wright EM. Expression cloning and cDNA sequencing of the $\mathrm{Na}^{+}$-glucose cotransporter. Nature 1987; 330: 379-81.

2 Tarpey PS, Wood IS, Shirazi-Beechey SP, Beechey RB. Amino acid sequence and the cellular location of the $\mathrm{Na}^{+}$dependent D-glucose symporters (SGLT1) in the ovine enterocyte and the parotid acinar cell. Biochem $\mathcal{F} 1995$; 312: $293-300$

3 Hediger MA, Turk E, Wright EM. Homology of the human intestinal $\mathrm{Na}^{+} /$glucose and Escherichia coli $\mathrm{Na}^{+} /$proline cotransporters. Proc Natl Acad Sci USA 1989; 86: 5748-52.

4 Shirazi-Beechey SP. Molecular biology of intestinal glucose transport. Nutr Res Rev 1995; 8: 27-41.

5 Turk E, Zabel B, Mundlos S, Dyer J, Wright EM. Glucose/ \begin{tabular}{l} 
galactose malabsorption caused by a defect in the $\mathrm{Na}^{+} /$ \\
\hline
\end{tabular}

6 Hirschhorn N, Greenough WB III. Progress in oral rehydration therapy. Sci Am 1991; 264: 50-6.

7 Ferraris RP, Diamond JM. Specific regulation of intestinal nutrient transporters by their dietary substrates. Ann Rev Physiol 1989; 51: 125-41.

8 Dyer J, Scott D, Beechey RB, Care AD, Abbas KS, ShiraziBeechey SP. Dietary regulation of intestinal glucose transport. In: Lentze MJ, Grand RJ, Naim HY, eds. Mammalian brush border membrane proteins. Part II. Stuttgart: Thieme Verlag, 1994: 65-72.

9 Lescale-Matys L, Dyer J, Scott D, Freeman TC, Wright EM, Shirazi-Beechey SP. Regulation of the ovine intestinal $\mathrm{Na}^{+}$/glucose co-transporter (SGLT1) is dissociated from mRNA abundance. Biochem $f$ 1993; 291: $435-40$.

specific activity and the abundance of lactase measured in BBMV isolated from both intestinal regions were identical (fig 3). The values for lactase activity measured in BBMV are similar to measurements reported from studies on other subjects. ${ }^{1625}$

The accumulated data indicate that the observed decline in the activity and abundance of SGLT1 in the dysfunctional tissue cannot be attributed entirely to any significant structural changes as the abundance of villin and the concentrations of lactase measured in the respective tissues remained unchanged. The activity and the expression of SGLT1 in human intestine, therefore, seems to be maintained by the presence of luminal nutrients. This finding is in accord with those obtained with the animal model systems. ${ }^{19} 20$

A recent report on the determination of SGLT1 mRNA expression in the intestinal tissue of malnourished infants with acquired monosaccharide intolerance (AMI), showed that the decline in SGLT1 mRNA observed in $\mathrm{AMI}$ is in excess of that owing to villus atrophy, as determined by levels of $\beta$-actin mRNA. ${ }^{26}$ The infants with AMI regained glucose tolerance when nutritional status was restored. These observations collectively emphasise the importance of dietary sugars in the regulation of the expression of the intestinal sugar transporter. Further work on the mechanisms by which dietary sugar regulates the expression of the human SGLT1 gene will increase our understanding of how dietary components can affect intestinal function. This information will facilitate studies into many digestive and absorptive diseases of the intestine.

The financial support of The Wellcome Trust and Tenovus are gratefully acknowledged. Antibody to lactase was kindly provided by Dr Dallas Swallow, London, UK, and the antibody to sucrase was a kind gift from Dr Suzanne Maroux, Marseilles, France. SP Shirazi-Beechey is a Wellcome Trust Senior Lecturer. This work has been described in a preliminary communication (Gut 1996; 38: A22.) presented at the British Society of Gastroenterology Spring meeting, Brighton, UK, March 1996.
10 Shirazi-Beechey SP, Davies AG, Tebbutt K, Dyer J, Ellis A, Taylor CJ, et al. Preparation and properties of brushborder membrane vesicles from human small intestine. Gastroenterology 1990; 98: 676-85.

11 Shirazi-Beechey SP, Kemp RB, Dyer J, Beechey RB. Changes in the functions of the intestinal brush border membrane during the development of the ruminant habit in lambs. Comp Biochem Physiol 1989; 94B: 801-6.

12 Shirazi-Beechey SP, Smith MW, Wang Y, James PS. Postnatal development of lamb intestinal digestive enzymes is not regulated by diet. $\mathcal{f}$ Physiol 1991; 437: $691-8$

13 Koldovsky O, Asp NG, Dahlqvist A. A method for the separate assay of neutral and acid beta-galactosidase in homogenates of rat small-intestinal mucosa. Anal Biochem homogenates of rat

14 Shirazi-Beechey SP, Dyer J, Allison G, Wood IS. Nutrient regulation of intestinal sugar-transporter expression. Biochem Soc Trans 1996; 24: 389-92.

15 Robine S, Huet CM, Moll R, Sahuquillo-Merino C, Coudrier E, Zweibaum A, et al. Can villin be used to identify malignant and undifferentiated normal digestive epithelial cells? Cell Biol 1985; 82: 8488-92.

16 Gorvel JP, Ferrero A, Chambraud L, Rigal A, Bonicel J, Maroux S. Expression of sucrase-isomaltase and dipeptidylpeptidase IV in human small intestine and colon. Gastroenterology 1991; 101: 618-25

17 Maiuri L, Raia V, Potter J, Swallow D, Ho MW, Fiocca R, et al. Mosaic pattern of lactase expression by villous enterocytes in human adult-type hypolactasia. Gastroenterology 1991; 100: 359-69.

18 Davidson NO, Hausman AML, Ifkovits CA, Buse JB, Gould GW, Burant CF, et al. Human intestinal glucose transporter expression and localisation of GLUT5. Am $\mathcal{f}$ Physiol 1992; 262: C795-800.

19 Shirazi-Beechey SP. Intestinal sodium-dependent Dglucose cotransporter: Dietary regulation. Proc Nutr Soc 1996; 55: 167-78.

20 Shirazi-Beechey SP, Hirayama B, Wang Y, Scott D, Smith MW, Wright EM. Ontogenic development of lamb intestinal sodium-glucose co-transporter is regulated by diet. F Physiol 1991; 437: 699-707.

21 Burant CF, Saxena M. Rapid reversible substrate regulation of fructose transporter expression in rat small intestine and kidney. Am f Physiol 1994; 267: G71-9

22 Henning SJ, Rubin DC, Shulman RJ. Ontogeny of the intestinal mucosa. In: Johnson LR, ed. Physiology of the intestinal mucosa. In: Johnson LR, ed. Physiology of the
gastrointestinal tract. 3rd edn. New York: Raven Press, 1994: 571-610

23 Duluc I, Freund IN, Leberquier C, Kedinger M. Fetal endoderm primarily holds the temporal and positional information required for mammalian intestinal development. F Cell Biol 1994; 126: 211-21. associated protein of the intestinal microvillus. Proc Nat Acad Sci USA 1979; 76: 2321-5.

25 Dahlqvist A. Method for assay of intestinal disaccharidases. Anal Biochem 1964; 7: 18-25.

26 Nichols BL, Dudley MA, Heath J, Lyman J, Avery S, Carrazza FR. Intestinal sodium glucose transporter (SGLT 1) mRNA levels in malnourished infants with acquired monosaccharide intolerance (AMI) [abstract] Mol Biol Cell 1995; 78 (suppl): 457.
24 Bretscher A, Weber K. Villin: the major microfilament- 